\title{
Near-Net-Shape Production of Hollow Titanium Alloy Components via Electrochemical Reduction of Metal Oxide Precursors in Molten Salts
}

\author{
DI HU, WEI XIAO, and GEORGE Z. CHEN
}

\begin{abstract}
Metal oxide precursors (ca. 90 wt pet Ti, 6 wt pet Al, and 4 wt pct V) were prepared with a hollow structure in various shapes such as a sphere, miniature golf club head, and cup using a one-step solid slip-casting process. The precursors were then electro-deoxidized in molten calcium chloride $\left[3.2 \mathrm{~V}, 1173 \mathrm{~K}\left(900{ }^{\circ} \mathrm{C}\right)\right]$ against a graphite anode. After 24 hours of electrolysis, the near-net-shape Ti-6Al-4V product maintained its original shape with controlled shrinkage. Oxygen contents in the Ti-6Al-4V components were typically below $2000 \mathrm{ppm}$. The maximum compressive stress and modulus of electrolytic products obtained in this work were approximately $243 \mathrm{MPa}$ and $14 \mathrm{GPa}$, respectively, matching with the requirement for medical implants. Further research directions are discussed for mechanical improvement of the products via densification during or after electrolysis. This simple, fast, and energy-efficient near-net-shape manufacturing method could allow titanium alloy components with desired geometries to be prepared directly from a mixture of metal oxides, promising an innovative technology for the low-cost production of titanium alloy components.
\end{abstract}

DOI: $10.1007 / \mathrm{s} 11663-013-9800-5$

(C) The Author(s) 2013. This article is published with open access at Springerlink.com

\section{INTRODUCTION}

TITANIUM metal and its alloys exhibit high specific strength, light weight, outstanding biocompatibility, and excellent corrosion resistance. ${ }^{[1,2]}$ However, due to the inherent costliness, they are seriously restricted to critical and demanding niche applications, ${ }^{[3]}$ such as the aeroplanes, ${ }^{[4]}$ medical implants, ${ }^{[5]}$ and performanceimproving sports equipment. ${ }^{[6]}$ Broadly speaking, the high cost of titanium and its alloys arises from two factors: the energy- and labor-intensive extraction of titanium metal (sponge) via the Kroll Process ${ }^{[7]}$ (6 to 29 $\$ / \mathrm{kg}$ depending on demand) and the complex and expensive downstream processes for alloying and manufacturing of the final components (10 to 30 times of the sponge value) ${ }^{[8]}$

The cost of the post-extraction alloying processes is significant, because the wide differences in the melting points and densities of the alloying elements necessitate multiple remelting steps to insure homogeneity of the final alloys. Furthermore, due to the high affinity to oxygen and the poor workability of titanium and its

DI HU, Postdoctoral Research Fellow, and GEORGE ZHENG CHEN, Professor of Electrochemical Technologies, are with the Department of Chemical and Environmental Engineering, and Energy and Sustainability Research Division, Faculty of Engineering, University of Nottingham, University Park, Nottingham, NG7 2RD UK, Contact e-mail: george.chen@nottingham.ac.uk WEI XIAO, formerly Postdoctoral Research Fellow, University of Nottingham, is now Associate Professor in School of Resource and Environmental Science, Wuhan University, Wuhan 430072, P.R. China.

Manuscript submitted April 23, 2012.

Article published online February 12, 2013. alloys, the downstream shaping processes are also beset with difficulties, which drastically increase the cost of the final components. ${ }^{[2]}$ For instance, the cost of downstream processes for the production of a $2.54-\mathrm{cm}$-thick titanium alloy plate accounts for 62 pct of the total cost ${ }^{[8]}$ fabrication of more complex shapes is of course more expensive, constituting a commensurately greater proportion of the bottom-line figure. Consequently, in recent years, the primary focus in titanium technology development has been the production of cost-affordable titanium and titanium alloy components rather than the development of new alloys with enhanced properties. ${ }^{[9]}$ The results are two research routes: devising novel methods for the extraction of titanium metal and developing creative techniques for the fabrication of titanium and its alloy components.

Over the last two decades, there have been approximately 20 newly proposed processes, some of which are being commercially developed, directed toward the lowcost extraction of titanium coupled with optimization of existing processes ${ }^{[8,10]} \mathrm{A}$ majority of these developments focus on the production of commercially pure titanium, with few having the capability to produce titanium alloys directly and fewer still having done so. Notable among these, the FFC-Cambridge Process ${ }^{[11]}$ has been successfully demonstrated to directly produce titanium metal and its alloys ${ }^{[12]}$ by the electrochemical reduction of a cathodic oxide precursor in a molten salt electrolyte. During this process, the ionized oxygen atoms are transferred via the molten salt from the cathode to the anode where they discharge as $\mathrm{CO} / \mathrm{CO}_{2}$ or $\mathrm{O}_{2}$ for graphite or inert anode materials, respectively. The FFC-Cambridge Process is capable of producing commercially pure titanium sponge $(<2000 \mathrm{ppm} \mathrm{O})$ at an 
energy consumption of ca. $20 \mathrm{kWh} / \mathrm{kg}$ or 60 pct less than the Kroll Process $(>50 \mathrm{kWh} / \mathrm{kg})$. $^{[13,14]}$

On the other hand, the concept of near-net-shape manufacturing has been developed-intermediates of engineering components are produced that are as "near" as possible to the desired final shape, requiring minimal additional processing. Cost-effective titanium and alloy parts have been produced using a variety of technologies, such as arc melting and casting, powder metallurgy, laser forming, conventional sheet forming, metal injection molding, and superplastic forming and diffusion bonding. ${ }^{[2,3]}$ Nevertheless, due to the inherent properties of titanium, there are lingering issues associated with these processes, such as the detrimental reactions of titanium with elements in the investments during the investment casting process ${ }^{[15]}$ and excessive oxygen contamination in titanium powder metallurgy owing to the increased surface area of the fine particles. ${ }^{[16]}$

The FFC-Cambridge Process has the ability to combine extraction of metals and synthesis of alloys into near-net-shape production. This was recently demonstrated in the production of $\mathrm{Zr}$ and $\mathrm{Zr}-2.5 \mathrm{Nb}$ tubes from their metal oxide precursors. ${ }^{[17]}$ This study applies this unique characteristic capability of the FFC-Cambridge Process in the near-net-shape manufacture of titanium alloy components in complex shapes, particularly hollow structures, directly from a mixture of metal oxides. The workhorse alloy, Ti-6Al-4V, has been chosen as the target due to its superior properties and majority share $(>50 \mathrm{pct})$ of the relevant market. ${ }^{[3]}$ In addition, a modified solid slip-casting process is described here for the fabrication of hollow metal oxide precursors of $\mathrm{Ti}-6 \mathrm{Al}-4 \mathrm{~V}$ in a single step.

\section{EXPERIMENTAL}

The procedure for preparation of the feedstock as described below was established through trial and error, with consideration of product quality and processing time. It proceeded by firstly ball milling the binary mixture of $\mathrm{TiO}_{2}\left(\geq 99\right.$ pct, Sigma-Aldrich) and $\mathrm{V}_{2} \mathrm{O}_{3}(\geq 99$ pct, Acros Organics) in isopropyl alcohol ( $\geq 99.7$ pct, Sigma-Aldrich) using a zirconia milling set at $600 \mathrm{rpm}$ for 30 minutes. Secondly, $\mathrm{Al}_{2} \mathrm{O}_{3}$ (>99 pct, Logitech) was added to form the ternary metal oxide mixture with a mass ratio equivalent to ca. 90 wt pet $\mathrm{Ti}, 6$ wt pet $\mathrm{Al}$, and $4 \mathrm{wt}$ pet $\mathrm{V}$. The mixture was milled at $300 \mathrm{rpm}$ for a further 5 minutes. Thirdly, the ball-milled feedstock was dried in a fume cupboard and subsequently dispersed ultrasonically into distilled water to form a slip for solid slip-casting. The molds were prepared from Plaster of Paris, $\mathrm{CaSO}_{4} \cdot 2 \mathrm{H}_{2} \mathrm{O}$ (general purpose grade, Anita's) in a $1: 1$ mass ratio with water.

The slip-cast metal oxide precursor was placed in a titanium basket to form an assembled cathode for electro-deoxidation. A graphite rod $(10 \times 100 \mathrm{~mm}, \mathrm{HK}-$ 3 , Tokai carbon) was used as the anode, while molten $\mathrm{CaCl}_{2}$ was used as the electrolyte. Anhydrous $\mathrm{CaCl}_{2}$ was prepared from $\mathrm{CaCl}_{2} \cdot 2 \mathrm{H}_{2} \mathrm{O}$ ( $\geq 99$ pct, Sigma-Aldrich) by heating at a rate of $0.8 \mathrm{~K}\left(0.8{ }^{\circ} \mathrm{C}\right) \mathrm{min}^{-1}$ from room temperature to $423 \mathrm{~K}\left(150{ }^{\circ} \mathrm{C}\right)$ where it was held for
$20 \mathrm{~h}$ under vacuum (ca. $-96 \mathrm{kPa}$ ). The dried salt was then contained in either an alumina (CL80, Almath) or a stainless steel crucible which was then placed into a sealable stainless steel retort housed in a programmable vertical tube furnace (Vecstar Furnaces Ltd.). The temperature was ramped to $573 \mathrm{~K}\left(300{ }^{\circ} \mathrm{C}\right)$ and held for several hours in air, after which the vessel was sealed and continuously flushed with argon, while ramping to the operating temperature of $1173 \mathrm{~K}\left(900{ }^{\circ} \mathrm{C}\right)$. Electrodeoxidation was conducted at $3.2 \mathrm{~V}$ for 24 hours using a 2-electrode system (Agilent power supply E3633A). After electrolysis, the cathode was lifted from the molten salt to the upper cooler zone, while the system was cooled to room temperature under a flow of argon. The electrolysis product was then removed from the reactor, washed in distilled water, and dried in air.

Cyclic voltammetry (CV) was performed on a PGSTAT30 Autolab Potentiostat (Eco Chemie, Inc). A molybdenum (Mo) wire (99.95 pct, $1 \mathrm{~mm}$ in diameter, Goodfellows) was used as the pseudo-reference electrode. The potential shift of this pseudo-reference was found to be less than $5 \mathrm{mV}$ during the period of the $\mathrm{CV}$ test (ca. 2 hours). A notched Mo wire was then loaded with the metal oxides, as described in detail elsewhere, ${ }^{[18,19]}$ and used as the working electrode for recording cyclic voltammograms (CVs) in molten $\mathrm{CaCl}_{2}$ at $1123 \mathrm{~K}\left(850^{\circ} \mathrm{C}\right)$.

Sample analyses were carried out using scanning electron microscopy (SEM, Philips XL30 FEG), back scattered electron imaging-scanning electron microscopy (BSE-SEM, FEI Quanta 600 ESEM), X-ray diffraction (XRD, DG3 Cu-Ka generator, scan range: 20-80 deg), and energy-dispersive X-ray spectroscopy (EDX, EDAX Genesis 2000). Inert-gas fusion-infrared absorption oxygen analysis (RO-416DR, LECO) was used to detect the oxygen content in the electrolytically produced samples. Compression tests were conducted on an Instron-type test machine (Instron 5581).

\section{RESULTS AND DISCUSSION}

\section{A. Mold Design and Solid Slip-casting}

The plaster mold was made in two segments, each of which has a hemi-spherical cavity in the center. A 16-mmdiameter spherical cavity can be formed inside the plaster mold when combining these two parts together. Two small holes, which served as the channels for slip injection and gas releasing, were drilled on the top part of the mold. The mold was sized so that it could be separated after the solid slip-casting process without damaging the fragile slip-cast metal oxide precursor. The slip was prepared by mixing the ball-milled metal oxide mixture with distilled water to a mass ratio of $1: 1.5$, e.g., $3 \mathrm{~g}$ of metal oxide mixture with $4.5 \mathrm{ml}$ water. As the volume of the spherical cavity inside the mold was ca. $2 \mathrm{ml}$, while that of the prepared slip was ca. $4.5 \mathrm{ml}$, a syringe was used to slowly and continuously inject the slip into the mold, giving enough time for water absorption by the plaster. Inevitably during this process, some spillage of the slip was observed at the gas release hole, as well as minor leakage at the connection between 
the top and bottom parts of the mold. The mass of the final slip-cast metal oxide precursor was approximately $2 \mathrm{~g}$. At the final stages of slip injection, the gas-releasing hole was sealed quickly by the solidifying slip due to the small quantity of slip permitting rapid water drainage. The syringe needle was kept in the injection hole during the process to create a hole on the cast, which would facilitate post-reduction washing. Figures 1(a) through (c) illustrates schematically this solid slip-casting method. Once the slip was injected into the mold, the water was removed by capillary action (Figure 1(a)), leaving a close-packed deposit of metal oxide particles against the inner wall. As this draining process proceeded continuously, a cavity was generated in the upper central part of the slip due to the influence of gravity (Figure 1(b)); this would result in an uneven wall thickness in the produced precursor. To insure uniform thickness, the plaster mold was rotated several times during the process (Figure 1(c)). Following casting, the plaster mold was dried in a fume cupboard for $48 \mathrm{~h}$, after which the syringe needle was removed, the mold opened, and the precursor exposed as shown in Figure 1(d). The slip-cast metal oxide precursor was spherical in shape with a slightly reduced diameter of approximately $15.6 \mathrm{~mm}$; this allowed it to be easily released from the plaster mold due to contraction during the drying process. The hollow structure of the precursor can be seen in Figure 1(e), where one such precursor was intentionally fractured.

Other precursor shapes were also prepared, e.g., a pellet and cup, for electro-deoxidation under the same conditions to further demonstrate the feasibility of the FFC-Cambridge Process for near-net-shape production of Ti-6Al-4V components. Figures 2(a) through (f) depicts the solid slip-casting process for producing metal oxide precursors in either of these shapes.

In the slip-casting process, different mass ratios of the metal oxide mixture to water were investigated, including $1: 1,1: 1.25,1: 1.85$, and $1: 2.5$. The ratio was found to be a crucial parameter for the slip-casting of cup-shaped precursors. The generated slips were poured into plaster molds (ca. $13 \mathrm{~mm}$ in diameter and $13 \mathrm{~mm}$ in depth) as shown in Figures 2(d) through (f). To examine the wall thickness of the cast piece, the precursors were first immersed in epoxy and after solidifying for 24 hours, the samples were polished using alumina paste to explore the cross section. Figure 3 presents cross sections of four slipcast metal oxide precursors made from slips with different mass ratios of metal oxide mixture to water.

The cross-sectional images presented in Figure 3 indicate that the mass ratio of metal oxide mixture to water should be controlled in a specific range in order to obtain a uniform wall thickness across the part. Based on these observations, when the mass ratio was at or above 1:1.25, the slip-cast metal oxide precursor tended to form a tapered wall shape, lacking in thickness control (Figures 3(a) and (b)). This was thought to be due to the rapidity of casting resulting from the small quantity of water in the slip. ${ }^{[20]}$ Conversely, when the mass ratio was slightly decreased to either $1: 1.85$ or $1: 2.5$, a relatively uniform wall thickness could be achieved (Figures 3(c) and (d)). It should be noted that if the prepared slip is too dilute, variations in thickness and density across the part may occur due to settling. Therefore, the ideal ratio for slip-casting of these parts was found to be in the range of $1: 1.85$ to $1: 2.5$. Additionally, the porosity of slip-cast metal oxide precursors was in
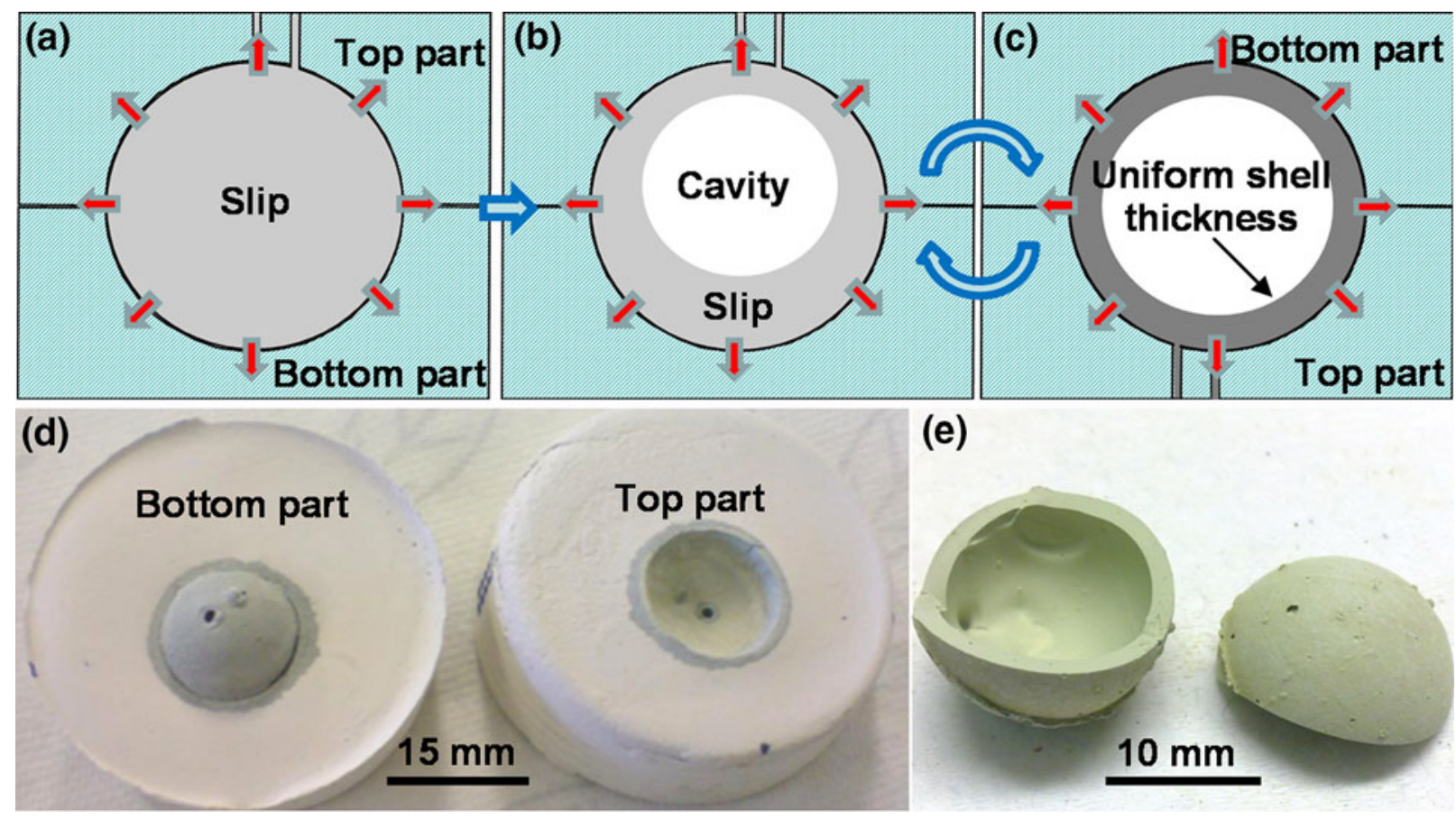

(e)

Fig. 1- (a) through $(c)$ Schematic illustration of the cross section of the plaster mold with slip during the solid slip-casting process for producing precursors in a hollow sphere shape, $(d)$ photograph of a slip-cast metal oxide precursor in the designed plaster mold, and $(e)$ the fractured sphere showing the hollow structure. 


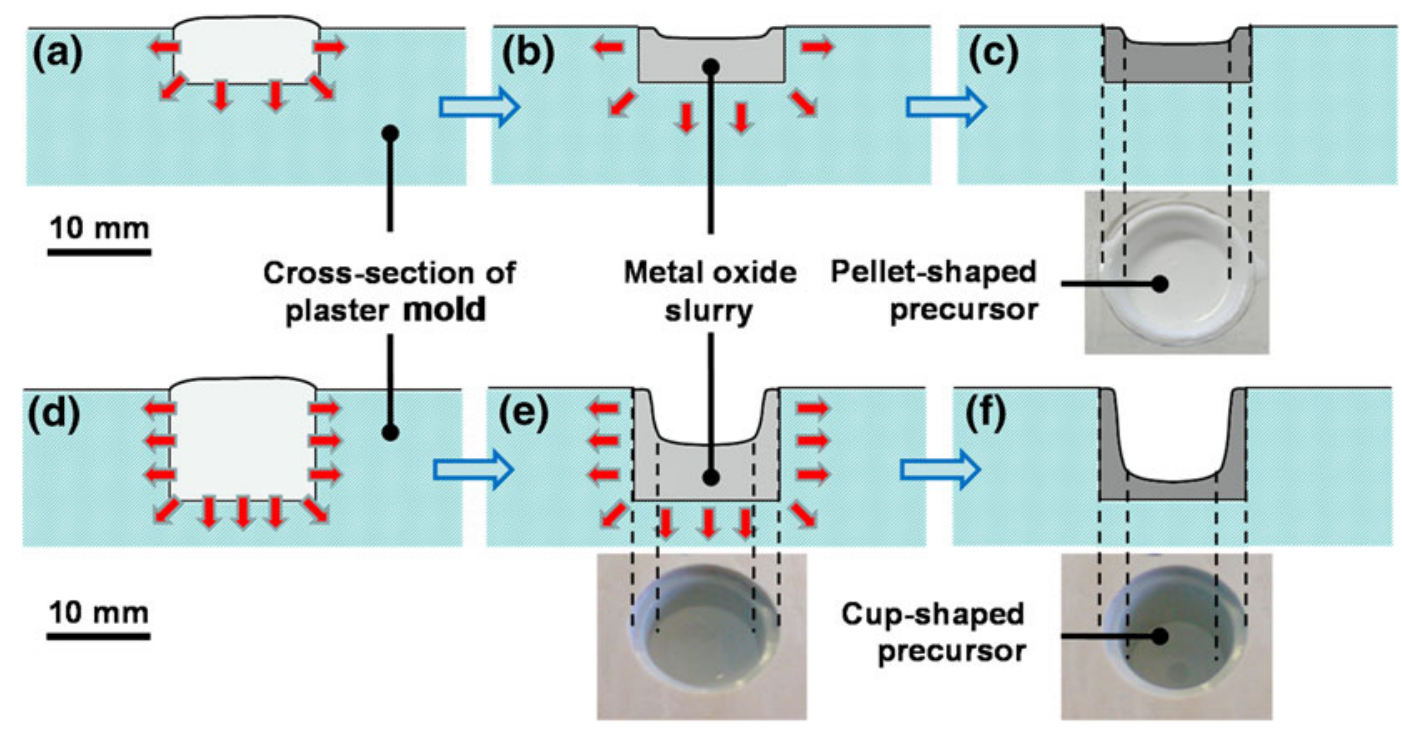

Fig. 2-(a) through $(f)$ Schematic illustration of the cross section of a plaster mold containing slip during the solid slip-casting process for producing precursors in the (a) through (c) pellet or (d) through (f) cup shape.
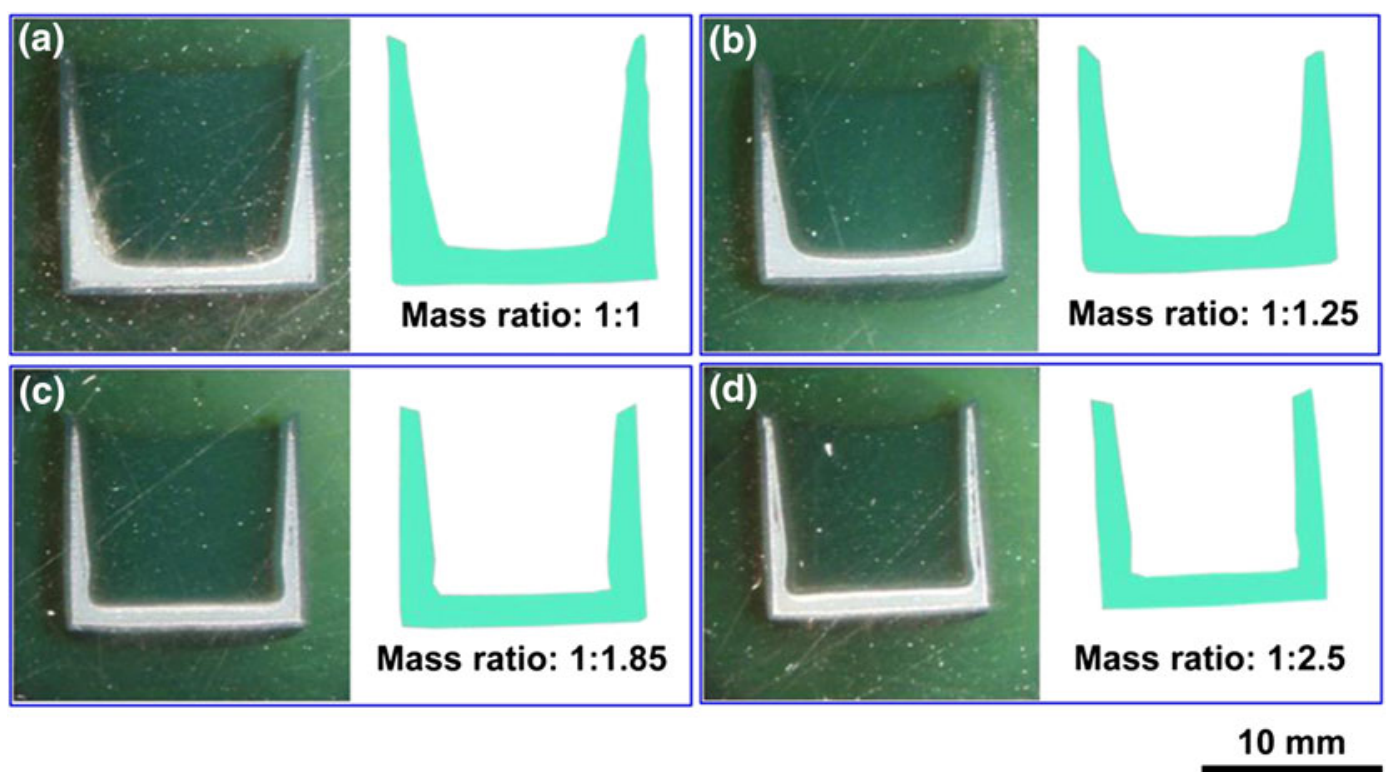

Fig. 3 - Cross sections of precursors prepared from different mass ratios of metal oxide to water: (a) 1:1, (b) 1:1.25, (c) 1:1.85, and (d) 1:2.5.

the range of 55 to 60 pct, which would facilitate the movement of electrolyte in the precursor during electrolysis. Figure 4(a) shows a cup-shaped metal oxide precursor (ca. $1.5 \mathrm{~g}$ ) which was cast from a slip with a mass ratio 1:1.85; the top surface of the slip-cast part was polished to make it flatter, facilitating better contact with the cathode current collector assembly. This precursor was $10.4 \mathrm{~mm}$ high (after polishing the top surface), with a $12.8 \mathrm{~mm}$ OD, and a wall thickness of ca. $1.72 \mathrm{~mm}$. SEM analysis of this part (Figure 4(b)) shows that the ball-milled metal oxide mixture exhibited a sub-micron particle size uniformly distributed in the range of 0.2 to $0.7 \mu \mathrm{m}$.

\section{B. Cathode Design}

The metal oxide precursors investigated in this study were relatively fragile and could not be attached to the cathode current collector using metal meshes and wires as reported before. ${ }^{[11,13]}$ Placing the precursor at the bottom of the graphite or metal crucible used as the current collector ${ }^{[11,21]}$ was also infeasible as the metal oxide precursor could float owing to the buoyancy provided by the hollow cavity. Therefore, a basket cathode design was developed to offer both mechanical protection and electric contact to the precursor. 


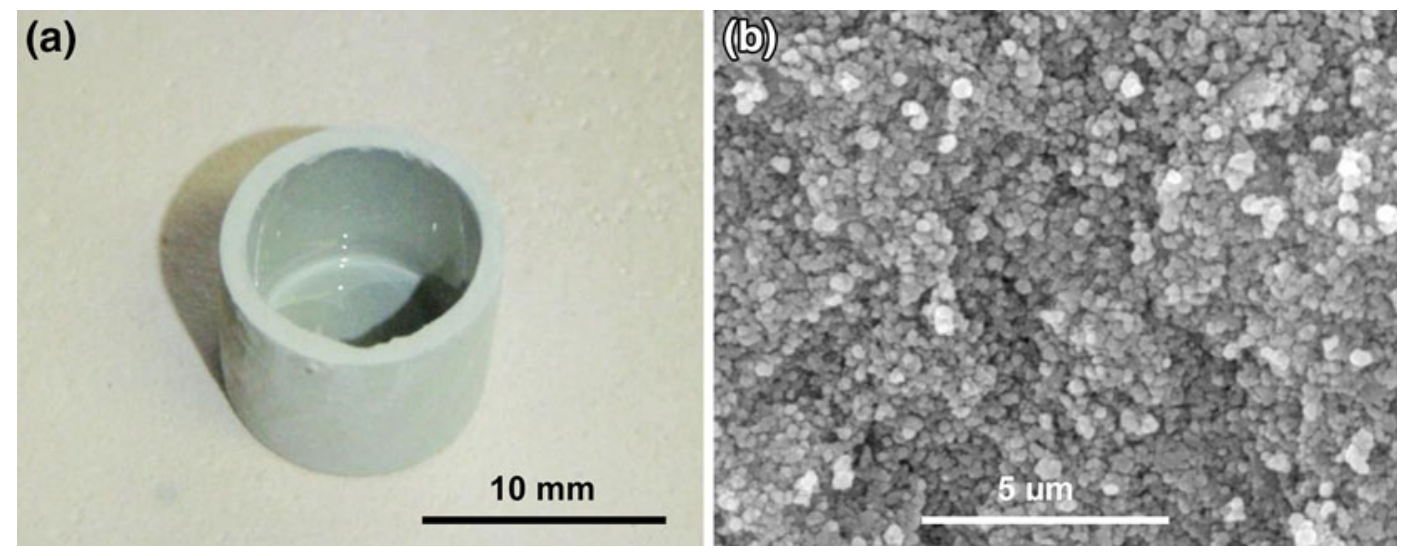

Fig. 4 - (a) Slip-cast cup-shaped metal oxide precursor from a slip with a 1:1.85 mass ratio of metal oxide mixture to water, $(b)$ SEM image of metal oxide precursor.

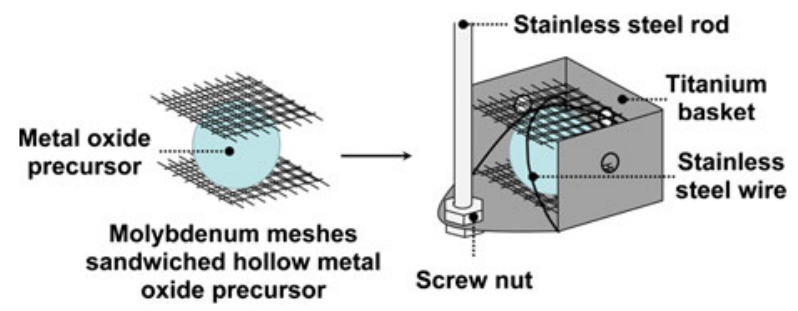

Fig. 5-Schematic illustration of cathode design for fragile hollow metal oxide precursors.

The oxide precursor was placed between two molybdenum (Mo) meshes and contained inside a titanium (Ti) basket holder ( $0.5 \mathrm{~mm}$ thickness) which had several drilled holes to facilitate molten salt movement during electrolysis. Stainless steel wire was gently wrapped around the holder to secure the Mo mesh-sandwiched precursor. The cathode assembly was then attached to a threaded stainless steel rod using screw nuts as illustrated in Figure 5. Based on experimental observations, both the Mo meshes and $\mathrm{Ti}$ basket holder could be reused for more than 3 times with careful washing and polishing after each electrolysis experiment.

In the FFC-Cambridge Process, sintering of the green precursors is a standard pretreatment to ensure sufficient mechanical strength is attained for handling. However, the decreased porosity as a result of the sintering process impedes the electrolyte infiltration and movement in the pores, hindering the electro-deoxidation process. Although fugitive agents have sometimes been employed to generate high porosity in the sintered precursors, ${ }^{[14,22]}$ the energy consumption of the sintering process remains a concern. Fortunately, by taking advantage of this cathode design, no additional sintering was required for successful electrolysis.

\section{Electrochemical Reduction}

Electrolysis of the oxide precursor was performed at $3.2 \mathrm{~V}$ and $1173 \mathrm{~K}\left(900{ }^{\circ} \mathrm{C}\right)$ in molten $\mathrm{CaCl}_{2}$ for about 24 hours under argon. Based on previous studies, these conditions are sufficient to achieve complete reduction of either pure $\mathrm{TiO}_{2}{ }^{[22,23]}$ or low-grade $\mathrm{TiO}_{2}$ precursors ${ }^{[13]}$ with similar feedstock masses. Considering voltage losses due to the resistance of electrodes, electrolyte, and other materials utilized in the cell (the "iR drop") at $1173 \mathrm{~K}\left(900{ }^{\circ} \mathrm{C}\right)$, the $3.2 \mathrm{~V}$ applied cell voltage should have been below the decomposition voltage of $\mathrm{CaCl}_{2}$ (i.e., $3.23 \mathrm{~V}$ ), but still sufficient to drive the reduction of each metal oxide component in the precursor as shown in Table I. ${ }^{[24]}$

Using the cell voltage of $\mathrm{TiO}_{2}$ to $\mathrm{Ti}_{3} \mathrm{O}_{5}$ as the reference, the potential for reducing the oxide to the respective product can be derived from Table 1. For example, the potentials are $-0.011 \mathrm{~V}$ for $\mathrm{V}_{2} \mathrm{O}_{3}$ to $\mathrm{VO}$ and $-0.155 \mathrm{~V}$ for $\mathrm{Ti}_{3} \mathrm{O}_{5}$ to $\mathrm{Ti}_{2} \mathrm{O}_{3}$ with reference to the reduction of $\mathrm{TiO}_{2}$ to $\mathrm{Ti}_{3} \mathrm{O}_{5}$. These are of course thermodynamic predictions, but can help understand the cathode reactions that can be revealed by cyclic voltammetry. Figure 6(a) presents a typical $\mathrm{CV}$ of pure $\mathrm{TiO}_{2}$ (solid line in Figure 6(a)), showing three main reduction peaks at $-0.37(\mathrm{C} 1),-0.52 \mathrm{~V}(\mathrm{C} 2)$, and $-1.23 \mathrm{~V}(\mathrm{C} 3)$ vs the Mo wire pseudo-reference. $\mathrm{C} 1$ and $\mathrm{C} 2$ can be attributed to the reactions of $\mathrm{TiO}_{2} \rightarrow \mathrm{Ti}_{3} \mathrm{O}_{5}$ (C1) $\rightarrow \mathrm{Ti}_{2} \mathrm{O}_{3}(\mathrm{C} 2)$, as their potential difference of $0.150 \mathrm{~V}$ agrees with the value of $0.155 \mathrm{~V}$ in Table I. It is worth noting that, between $\mathrm{TiO}_{2}$ and $\mathrm{Ti}_{2} \mathrm{O}_{3}$, there are many intermediates known as the Magneli phases, the stoichiometry of which varies according to the formula of $\mathrm{Ti}_{n} \mathrm{O}_{2 n-1}(n \geq 2) .^{[11,25,26]}$ Thus, $\mathrm{Ti}_{3} \mathrm{O}_{5}$ is only representative of the reduction of $\mathrm{TiO}_{2}$ to the Magneli phases.

Peak C3 is negatively shifted from $\mathrm{C} 1$ by $0.86 \mathrm{~V}$ and may be linked to $\mathrm{TiO} \rightarrow \mathrm{Ti}$ which should occur at $-0.896 \mathrm{~V}$ according to Table I. The small discrepancy, less than $0.04 \mathrm{~V}$, could be related to the fact that the $\mathrm{CV}$ of $\mathrm{TiO}_{2}$ in Figure 6(a) does not shown clearly the reduction of $\mathrm{Ti}_{2} \mathrm{O}_{3}$ to $\mathrm{TiO}$. A possible cause is the disproportionation of $\mathrm{Ti}_{2} \mathrm{O}_{3}$ to $\mathrm{TiO}$ and $\mathrm{TiO}_{2}{ }^{[25]}$ (or one of the Magneli phases). More likely, it is the in situ formation of perovskites as exemplified by the following reactions associated with $\mathrm{C} 1$ and $\mathrm{C} 2:^{[26-28]}$

$$
\mathrm{TiO}_{2}+2 \alpha e \leftrightarrow \mathrm{TiO}_{2-\alpha}+\alpha \mathrm{O}^{2-}(0 \leq \alpha \leq 0.5)
$$


Table I. Cell Voltages for the Anodic Formation of $\mathrm{CO}, \mathrm{CO}_{2}$, and $\mathrm{O}_{2}$, Calculated From Thermodynamic Data at $1173 \mathrm{~K}\left(900^{\circ} \mathrm{C}\right)^{[24]}$

Cell Voltage (V) for Anodic Formation of

\begin{tabular}{lcccr}
\cline { 2 - 4 } Oxide to Reduction Product & $\mathrm{CO}$ & $\mathrm{CO}_{2}$ & $\mathrm{O}_{2}$ & Potential $(\mathrm{V})$ vs $\mathrm{TiO}_{2} / \mathrm{Ti}_{3} \mathrm{O}_{5}$ \\
\hline $\mathrm{V}_{2} \mathrm{O}_{3}$ to $\mathrm{VO}$ & 0.229 & 0.320 & 1.346 & -0.011 \\
$\mathrm{VO}$ to $\mathrm{V}$ & 0.581 & 0.672 & 1.698 & -0.363 \\
$\mathrm{TiO}_{2}$ to $\mathrm{Ti}_{3} \mathrm{O}_{5}$ & 0.218 & 0.309 & 1.335 & 0.000 \\
$\mathrm{Ti}_{3} \mathrm{O}_{5}$ to $\mathrm{Ti}_{2} \mathrm{O}_{3}$ & 0.373 & 0.464 & 1.490 & -0.155 \\
$\mathrm{Ti}_{2} \mathrm{O}_{3}$ to $\mathrm{TiO}$ & 0.623 & 0.714 & 1.740 & -0.405 \\
$\mathrm{TiO}^{\mathrm{T}} \mathrm{Ti}$ & 1.114 & 1.205 & -0.896 \\
$\mathrm{Al}_{2} \mathrm{O}_{3}$ to $\mathrm{Al}$ & 1.135 & 1.226 & 2.231 & -0.917 \\
\hline
\end{tabular}

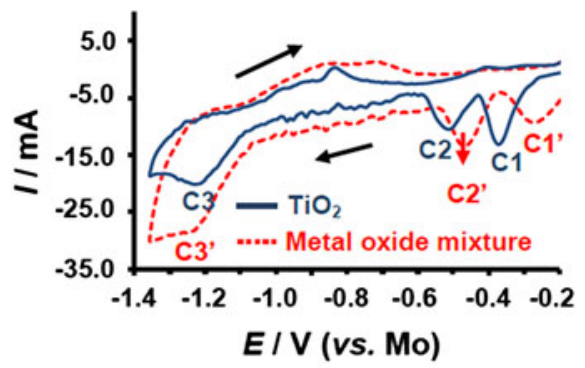

(a)

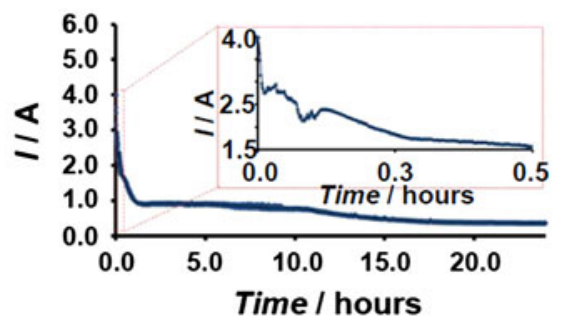

(b)

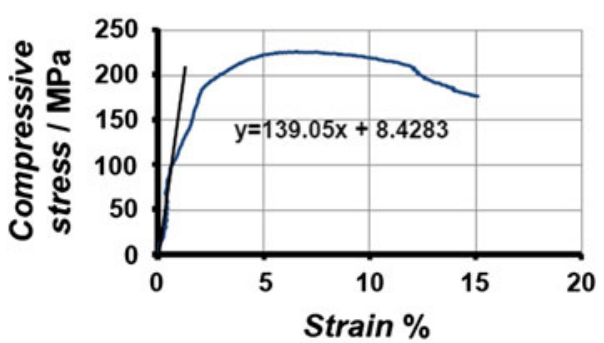

(c)

Fig. 6-(a) CVs of the Mo electrode loaded with $\mathrm{TiO}_{2}$ (solid line) and the metal oxide mixture (ca. 88.7 wt pet $\mathrm{TiO}_{2}, 7.4$ wt pct $\mathrm{Al}_{2} \mathrm{O}_{3}$, and 3.9 wt pet $\left.\mathrm{V}_{2} \mathrm{O}_{3}\right)$ (dashed line) at $1123 \mathrm{~K}\left(850^{\circ} \mathrm{C}\right)$. Scan rate: $20 \mathrm{mV} / \mathrm{s}$. (b) A typical current-time curve for 24 hours of reduction of a pellet-shaped oxide precursor (ca. $1 \mathrm{~g}$ ) using a titanium basket holder assembled cathode in molten $\mathrm{CaCl}_{2}$ at $1173 \mathrm{~K}\left(900{ }^{\circ} \mathrm{C}\right)$ at $3.2 \mathrm{~V}$. The inserted image is the enlarged portion of the larger panel. (c) Stress-strain curve of an electrolytic cup-shaped sample.

$$
\mathrm{TiO}_{2-\alpha}+\delta \mathrm{Ca}^{2+}+2 \delta e \leftrightarrow \mathrm{Ca}_{\delta} \mathrm{TiO}_{2-\alpha}(0 \leq \delta \leq 0.5)
$$

$$
\mathrm{TiO}_{2-\alpha}+\mathrm{Ca}^{2+}+\mathrm{O}^{2-}(\text { or } \mathrm{CaO}) \leftrightarrow \mathrm{CaTiO}_{3-\alpha}
$$

where $\alpha$ is $1 / 3$ for $\mathrm{Ti}_{3} \mathrm{O}_{5}$ and $1 / 2$ for $\mathrm{Ti}_{2} \mathrm{O}_{3}$, and can be 0 for $\mathrm{TiO}_{2}$ in Eqs. [2] and [3]. Clearly, Eq. [3] is a chemical reaction (i.e., it does not contribute to the current on the $\mathrm{CV}$ ) and only occurs after Eq. [1] which provides $\mathrm{O}^{2-}$, while $\mathrm{Ca}^{2+}$ comes from the molten salt. ${ }^{[26,28]}$ Further reduction of these perovskite phases may proceed directly to $\mathrm{TiO}^{[27]}$ which can explain the absence of the $\mathrm{Ti}_{2} \mathrm{O}_{3}$ to $\mathrm{TiO}$ reduction on the CV in Figure 6(a).

Interestingly, when compared with $\mathrm{C} 1$ and $\mathrm{C} 2$, the reduction peaks $\mathrm{C1}^{\prime}$ and $\mathrm{C}^{\prime}$ on the $\mathrm{CV}$ of the metal oxide mixture (dashed line in Figure 6(a), $88.7 \mathrm{wt}$ pct $\mathrm{TiO}_{2}, 7.4$ wt pet $\mathrm{Al}_{2} \mathrm{O}_{3}$, and 3.9 wt pet $\mathrm{V}_{2} \mathrm{O}_{3}$ ) shifted positively from -0.37 to $-0.28 \mathrm{~V}$ and -0.52 to $-0.48 \mathrm{~V}$, respectively. However, $\mathrm{C} 3$ and $\mathrm{C}^{\prime}$ still share almost the same potential $(-1.23 \mathrm{~V} v s-1.24 \mathrm{~V})$. These voltammetric changes can be regarded as the reduction of the oxide mixture being easier than that of pure $\mathrm{TiO}_{2}$ and warrant an analysis on the causes.

According to Table I, the reduction of $\mathrm{Al}_{2} \mathrm{O}_{3}$ to $\mathrm{Al}$ alone occurs at a more negative potential than $\mathrm{TiO}$ to $\mathrm{Ti}$. Also, $\mathrm{V}_{2} \mathrm{O}_{3}$ to $\mathrm{VO}$ occurs at almost the same potential as that for the reduction of $\mathrm{TiO}_{2}$ to $\mathrm{Ti}_{3} \mathrm{O}_{5}$, and $\mathrm{VO}$ to $\mathrm{V}$ occurs at a potential close to that of $\mathrm{Ti}_{2} \mathrm{O}_{3}$ to TiO. Thus, the reduction of $\mathrm{Al}_{2} \mathrm{O}_{3}$ or $\mathrm{V}_{2} \mathrm{O}_{3}$ alone is not expected to contribute to the positive potential shift of $\mathrm{C} 2$ and $\mathrm{C} 3$ in Figure 6(a). Incidentally, positive shifts of $\mathrm{C} 1$ and $\mathrm{C} 2$ were also observed when $\mathrm{CaTiO}_{3}$ was added to $\mathrm{TiO}_{2}$ to prevent in situ formation of the perovskites as represented by Eqs. [2] and [3]. ${ }^{[27]}$ The consequence of Eqs. [2] and [3] is the inclusion of $\mathrm{Ca}^{2+}$ which causes volume expansion and hence partial or complete blockage of the pores in the cathode. This in turn slows down or even stops the removal and/or supply of ions $\left(\mathrm{O}^{2-}\right.$ and $\left.\mathrm{Ca}^{2+}\right)$ via diffusion through the molten salt (electrolyte) in the pores, making the electro-reduction more difficult.

Obviously, the occurrence of Eqs. [2] and [3] requires the presence of "free" $\mathrm{TiO}_{2}$ or one of the Magneli phases. In other words, if free $\mathrm{TiO}_{2}$ may be partially or fully replaced in the precursor by "compounded" $\mathrm{TiO}_{2}$ with another metal oxide, e.g., $\mathrm{V}_{2} \mathrm{O}_{3}$ or $\mathrm{Al}_{2} \mathrm{O}_{3}$, in situ formation of perovskites can be difficult or avoided, resulting in easier reduction. To confirm this hypothesis, XRD patterns of ball-milled metal oxide mixture before and after sintering at $1173 \mathrm{~K}\left(900^{\circ} \mathrm{C}\right)$ in air are displayed in Figures 7(a) and (b), respectively. It can be seen that, before and after sintering, almost no change occurred in the $\mathrm{Al}_{2} \mathrm{O}_{3}$ peaks, but all the $\mathrm{V}_{2} \mathrm{O}_{3}$ 


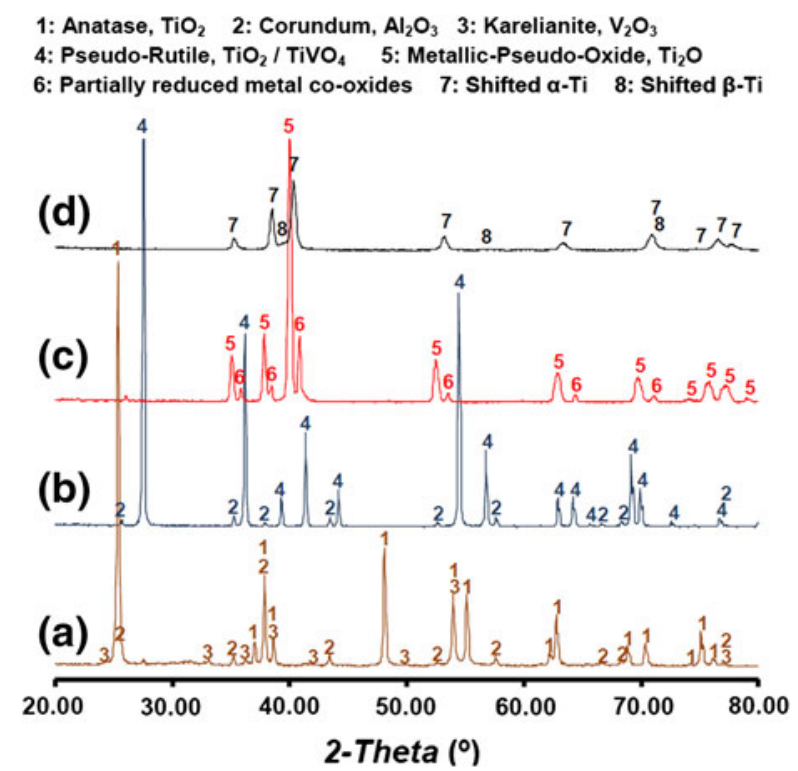

Fig. 7-XRD patterns of ball-milled metal oxide mixture $(a)$ before and $(b)$ after sintering $\left[2 \mathrm{~h}\right.$ in air at $\left.1173 \mathrm{~K}\left(900^{\circ} \mathrm{C}\right)\right]$ and $(c)$ partially [polarization for $6 \mathrm{~h}$ in $\mathrm{CaCl}_{2}$ at $1173 \mathrm{~K}\left(900{ }^{\circ} \mathrm{C}\right)$ ] and $(d)$ fully reduced [polarization for $24 \mathrm{~h}$ in $\mathrm{CaCl}_{2}$ at $1173 \mathrm{~K}\left(900{ }^{\circ} \mathrm{C}\right)$ ] pelletshaped mixed metal oxide precursor.

peaks disappeared. This is evidence that $\mathrm{Al}_{2} \mathrm{O}_{3}$ is nonreactive toward $\mathrm{TiO}_{2}$ and $\mathrm{V}_{2} \mathrm{O}_{3}$ under the applied sintering conditions. The absence of $\mathrm{V}_{2} \mathrm{O}_{3}$ peaks together with shifted rutile peaks observed in the postsintering sample indicates the formation of metal cooxides (or compounded oxide). The positions of shifted rutile peaks were found to be closer to that of $\mathrm{TiVO}_{4}$, indicating the possibility of conversion of anatase $\mathrm{TiO}_{2}$ and $\mathrm{V}_{2} \mathrm{O}_{3}$ into the pseudo-rutile phase, i.e., $\mathrm{TiO}_{2} / \mathrm{TiVO}_{4}$, at high temperatures.

Formation of $\mathrm{TiVO}_{4}$ in the oxide precursor is expected as the result of oxidation of V(III) to V(IV) during sintering in air. This oxidation would have brought oxygen into the precursor and caused volume expansion as $\mathrm{VO}_{1.5}\left(15.39 \mathrm{~cm}^{3} / \mathrm{mol}\right)$ is smaller than $\mathrm{VO}_{2}$ $\left(17.84 \mathrm{~cm}^{3} / \mathrm{mol}\right)$ in molar volume. However, the added amount of $\mathrm{V}_{2} \mathrm{O}_{3}(<4 \mathrm{wt}$ pct $)$ was small in the mixed oxide precursor, and the V(IV) formed was included in the lattice of the resulting pseudo-rutile phase of $\mathrm{TiO}_{2} /$ $\mathrm{TiVO}_{4}$. Thus, the oxidation of V(III) to V(IV) should have an insignificant effect on the actual overall volume of the mixed oxide precursors, particularly considering the volume shrinkage due to sintering which was always observed in this work.

To further investigate this mechanism, a partially reduced sample was subjected to XRD analysis. It was found that instead of the formation of perovskite (i.e., $\mathrm{CaTiO}_{3}$ ) which was found to be a reduction inhibitor, ${ }^{[14,27]}$ peaks of the metallic pseudo-oxide $\mathrm{Ti}_{2} \mathrm{O}$ and partially reduced metal co-oxide were observed (Figure 7(c)). Therefore, it can be concluded here that the formation of metal co-oxides or the pseudo-rutile phase (i.e., $\mathrm{TiO}_{2} / \mathrm{TiVO}_{4}$ ) during sintering of the oxide mixture could help diminish the formation of perovskite to some extent, bringing about easier electro-reduction.
In contrast to the positive shifts of $\mathrm{C} 1$ and $\mathrm{C} 2$, a slightly negative shift from -1.23 to $-1.24 \mathrm{~V}$ was observed on C3. However, the shift is clearly smaller than the difference between reduction of $\mathrm{TiO}$ to $\mathrm{Ti}$ and $\mathrm{Al}_{2} \mathrm{O}_{3}$ to Al. It indicates that the $\mathrm{Al}_{2} \mathrm{O}_{3}$ reduction occurred at a more positive potential in the mixed oxide electrode than that in Table I. This is evidence that the energy released from alloy formation, which is almost wasted in the conventional melting method, was utilized to lower the polarization for reduction and save energy. Further, at $1123 \mathrm{~K}\left(850{ }^{\circ} \mathrm{C}\right.$ ) (for recording the $\left.\mathrm{CV}\right), \mathrm{A} 1$ would be a liquid and, if formed, may flow away from the electrode. This obviously did not occur since analysis of the electrolytic alloys confirmed the designated $\mathrm{Al}$ concentration (see Section III-D). Thus, liquid Al was likely never formed, and the energy required to melt it for alloying is saved in electro-reduction.

A typical current-time curve recorded during constant-voltage electrolysis of the metal oxide precursor is presented in Figure 6(b). An initial current peak was observed (Figure 6(b), insert), in agreement with the three-phase interline (3PI) propagation mechanism featured in the FFC-Cambridge Process, ${ }^{[21]}$ with increased conductivity among the outer surface of the metal oxide precursor. ${ }^{[11]}$ However, when compared with previous observations, this initial current peak was less pronounced, ${ }^{[13,21]}$ possibly arising from the large contact area of the $\mathrm{Ti}$ basket coupled with a higher extra background current. The remainder of the current-time curve in Figure 6(b) matches well with that obtained from the reduction of pure $\mathrm{TiO}_{2}$ or different $\mathrm{TiO}_{2}$ precursors. ${ }^{[13,18]}$ This was expected as $\mathrm{TiO}_{2}$ accounted for ca. 88.7 pct of the slip-cast metal oxide precursor.

An intriguing question may be asked about the declining nature of the current in Figure 6(b). Is it because the "contact area" between the oxide and the metal formed decreases with time as electro-reduction approaches the core of the oxide precursor? In other words, if the current is normalized against the "contact area," could the "current density" remain constant? The answer is yes if diffusion is disregarded in the pores of the cathode according to the recently proposed three-phase interline (3PI) models. ${ }^{[21,29,30]}$ However, oxide ion diffusion through the pores in the formed metal layer would eventually become the control step in determining the overall speed of the reduction process when the metal layer becomes thicker with electrolysis. This effect of diffusion will lead to a declining current density. Of course, there are also other factors affecting the overall electrolysis current, such as temperature, voltage, molten salt composition, porosity, and particle sizes in the oxide precursor, formation of intermediate phases in the cathode, and the electronic conductivity in each part of the cell.

\section{Sample Characterization}

Figure 8 shows the photos of electrolytic products obtained from the molten salt electrolysis. After the solidified salt was removed by washing with water, the electrolytic products exhibited a dull gray color as shown in Figures 8(a) and (d). As expected, Figures 8(b), (e), and (h) confirm the metallic luster on all the metallized 

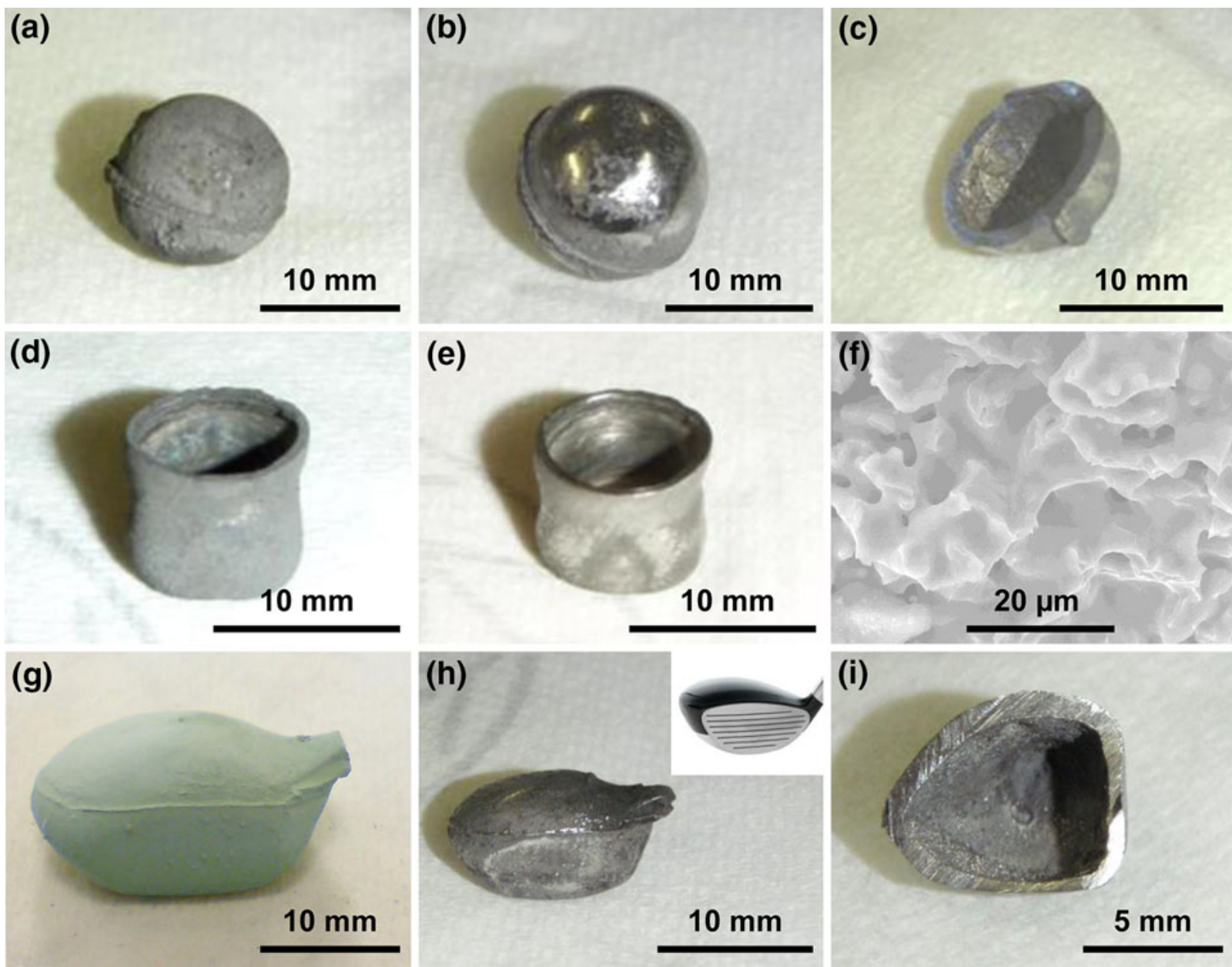

Fig. 8-Photographs of electrolytically produced $(a)$ Ti-6Al-4V hollow sphere before and $(b)$ after minor polishing, $(c)$ cross section of hollow sphere, $(d)$ cup-shaped Ti-6Al-4V before and $(e)$ after minor polishing, and $(f)$ SEM image of the interior structure of the electrolytically produced Ti-6Al-4V alloy. $(g)$ Golf club head-shaped metal oxide precursor, $(h)$ electrolytically produced miniature Ti-6Al-4V hollow golf club head. The inserted photo is the commercial titanium golf club driver head. (i) Cross section of produced miniature golf club head.

samples after a minor polish. As shown in Figure 7(d), XRD analysis proved that the obtained products were the $(\alpha+\beta)$ phase alloy. It is worth mentioning here that both $\alpha$ and $\beta$ phase peaks were slightly shifted which is common on commercial Ti-6Al-4V alloys ${ }^{[31]}$ owing to the given positions of $\alpha$ and $\beta$ phase being based on pure Ti rather than titanium alloys.

Actually, the observation of both the $\alpha$ and $\beta$ phases in the produced samples is expected because the electrolysis temperature $\left[1173 \mathrm{~K}\left(900{ }^{\circ} \mathrm{C}\right)\right]$ falls in the $\alpha$-to- $\beta$ phase equilibrium region of the Ti-6Al-4V alloy. Further increasing the temperature above the $\alpha$-to- $\beta$ phase transition temperature [ca. $1253 \mathrm{k}\left(980{ }^{\circ} \mathrm{C}\right)$ for the Ti$6 \mathrm{~A} 1-4 \mathrm{~V}$ alloy $]^{[3]}$ would be interesting as this may allow quenching the product to possess a higher proportion of the $\beta$ phase. Previous attempts to quench the Ti-6Al-4V alloy from $1323 \mathrm{~K}\left(1050{ }^{\circ} \mathrm{C}\right)$ resulted in the transformation to the martensite phase $^{[3]}$ which could be decomposed to separated $\alpha$ and $\beta$ phases by slow annealing at lower temperatures. ${ }^{[32]} \mathrm{A}$ recent study showed that it was possible to produce the TiZr alloy in the metastable $\beta$ phase or mixed $\alpha$ and $\beta$ phases by electro-reduction in the absence of any added $\beta$ stabi- liser. This unusual finding was attributed to the effects of quenching, but more importantly an appropriate amount of oxygen remaining in the alloy might have functioned as an inhibitor to the phase transition at low temperatures. ${ }^{[33]}$

It can be seen in Figures 8(a) through (e) that all electrolytic products retained the original shape of their metal oxide precursors (Figures 1(d) and 4(a)), while some shrinkage happened. The diameter of the electrolytically reduced hollow sphere was about 40 pct less than its metal oxide precursor, i.e., reduced from ca. $15.6 \mathrm{~mm}$ to ca. $9.4 \mathrm{~mm}$. The shrinkage of the electrolytic cup-shaped sample was approximately 23 pct in height and 13 pet in diameter. The shrinkage was mainly caused by the combined effects of solid-state sintering, change of density, and atomic rearrangement ${ }^{[22,34]}$ which occurred during electrolysis at $1173 \mathrm{~K}\left(900{ }^{\circ} \mathrm{C}\right)$. The shrinkage rates of the hollow sphere and cup-shaped samples were relatively consistent. Therefore, a desired size of the electrolytic product could be obtained by giving the metal oxide precursor a predefined allowance. Moreover, when compared with cup-shaped samples, the hollow spheres exhibited more regular contour 

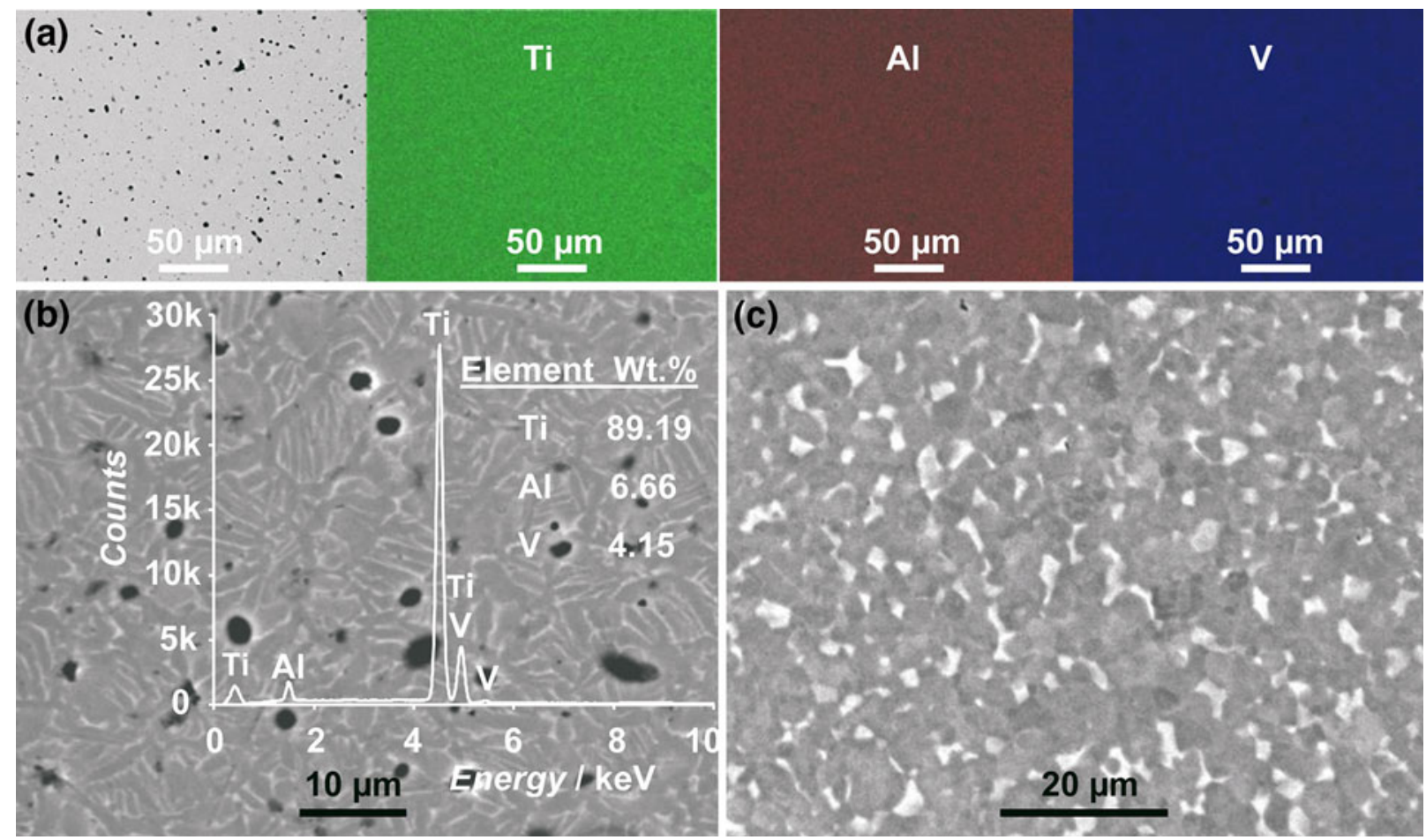

Fig. 9-BSE-SEM images of $(a)$ polished electrolytic product together with Ti, Al, and V EDX maps, $(b)$ polished sample investigated under higher magnification with insert of elemental composition, and (c) commercial Ti-6Al-4V sample.

shrinkage. This phenomenon could be ascribed to both the spherical shape which evenly distributes stress to avoid cracking and the inner cavity which functions as a cushion to bear more inward shrinkage. Figure 8(c) presents an electrolytically reduced hollow sphere which was sectioned with uniform wall thickness of ca. $1 \mathrm{~mm}$. The small hole generated during the slipcasting process permitted water access during postelectrolysis washing for salt removal. In addition, the electrolytic Ti-6Al-4V sample was broken by a pair of pliers to produce a fracture surface which was used to examine the interior structure under SEM. As shown in Figure 8(f), when compared with its metal oxide precursor (Figure 4(b)), the electrolytic Ti-6Al-4V exhibited a much less porous structure of heavily sintered nodular particles than in similarly prepared Ti metal. ${ }^{[11,35]}$ The average porosity of the electrolytic products was in the range of 26 to $30 \mathrm{pct}$, implying an enhanced mechanical strength, which will be discussed below. Furthermore, by simply changing the plaster mold to a golf club head shape, a miniature hollow golf club head-shaped metal oxide precursor was fabricated (Figure 8(g)). After $24 \mathrm{~h}$ of electrolysis $\left[3.2 \mathrm{~V}, 1173 \mathrm{~K}\left(900{ }^{\circ} \mathrm{C}\right)\right]$, a miniature hollow Ti-6Al-4V golf club head was obtained (Figures $8(\mathrm{~h})$ and (i)) which matches very well to the shape of a golf club driver head (see insert in Figure 8(h)).

Elemental composition and homogeneity are essential for titanium alloy properties. ${ }^{[36]}$ Typically, the oxygen content of the electrolytic products was approximately 1970 ppm as measured by the LECO RO-416DR, which was significantly lower than that of titanium components produced by powder metallurgy. ${ }^{[16]}$ A lower oxygen content can improve ductility.
For analyses of the other elements, the electrolysis products were sectioned, polished, and investigated under BSE-SEM, while EDX maps were recorded as shown in Figure 9(a). The black dots observed in the BSE-SEM images were due to the voids in the electrolytic products. The distribution of the alloying elements, i.e., Al and V, was relatively uniform. A typical BSESEM image and the associated EDX spectrum of the electrolytic samples are shown in Figure 9(b), together with elemental composition, confirming the samples to be Ti-6Al-4V. Moreover, both the SEM image in Figure 8(f) and the BSE-SEM image in Figure 9(b) revealed grain sizes of the produced alloy samples to be in the range between a few and a few tens of micrometers, much larger than the sizes of the particles in the mixed oxide precursor. This is interesting because the removal of oxygen from the metal oxide particles should have produced smaller metal particles. However, at the electrolysis temperature of $1173 \mathrm{~K}$ $\left(900{ }^{\circ} \mathrm{C}\right)$, sintering of small metal particles to a bigger grain size must have happened.

Nevertheless, when compared with that of a commercial Ti-6Al-4V sample (annealed, purchased from RollsRoyce $\left.^{(}\right)$as shown in Figure 9(c), a finer distribution of the $\alpha$ (dark) and $\beta$ (bright) phases is present across the electrolytic product. This was thought to have arisen from the solid-state reduction of the ball-milled metal oxide mixture with fine particle sizes and well-proportioned distribution of alloying elements.

All as-produced electrolytic Ti-6Al-4V alloy samples were subjected to mechanical tests. A typical compressive stress-strain curve, which was obtained from a cupshaped sample, is presented in Figure 6(c). It should be 
stated that the conditions, such as shape, dimension, and porosity, of the as-produced near-net-shape samples were not ideal for compression tests, which could have contributed to the noticeable fluctuations in Figure 6(c). However, there was always an approximate linear region on the stress-strain curve in the low stress region for all samples tested, which was used to derive the Young's modulus. The observed maximum compressive stress was ca. $243 \mathrm{MPa}$ and the corresponding modulus was ca. $14 \mathrm{GPa}$, which are relatively comparable with those of natural bones ( 2 to $200 \mathrm{MPa}$, and 0.1 to $20 \mathrm{GPa})^{[37]}$ and porous Ti-6Al-4V alloy produced by powder metallurgical techniques $(225 \mathrm{MPa}$, and $14 \mathrm{GPa}$ with 50 pct porosity). ${ }^{[38]}$ Therefore, it could be concluded that the electrolytic Ti-6Al-4V products exhibit enough strength to be directly used in some devices without further downstream processes such as smelting or pressing.

It is acknowledged that the samples produced in this work still contained too many voids as revealed by Figures 9(a) and (b) and obviously need further densification for high stress applications. While post-electrolysis improvement of the products may be achieved by high-pressure sintering (e.g., hot isotropic pressing), our follow-on research will focus on changing the electrolysis from one step to two steps. ${ }^{[14]}$ The first step will be same as that for electro-reduction with the second step being a prolonged period of in situ sintering. In the second step, a lower cell voltage may be applied to prevent reoxidation of the product without too much energy input. The temperature of the cell may also be increased in the second step to promote sintering, although this may be challenging in large-scale operation. Last, but not the least, precursor fabrication should be further investigated in relation to shape and property control in the near-net-shape product. Nevertheless, highly dense oxide precursor is not recommended unless the product is, for example, a thin-walled vessel. This is because, for reduction of a bulky precursor (e.g., $>2 \mathrm{~mm}$ in the thinnest dimension), a sufficiently porous structure is needed to enable the removal of oxygen ions at an acceptable speed through the molten salt in the pores, instead of the solid phase.

\section{CONCLUSIONS}

Ti-6Al-4V alloy components with complex shapes, such as hollow spheres and golf club heads, can be directly produced in the near-net shape from their metal oxide precursors via the FFC-Cambridge Process. An innovative plaster mold design is demonstrated for preparation of hollow oxide precursors by slip-casting. Results from preliminary studies by cyclic voltammetry and XRD analysis suggest that $\mathrm{V}_{2} \mathrm{O}_{3}$ can assist the reduction of $\mathrm{TiO}_{2}$ by preventing in situ formation of perovskites (e.g., $\mathrm{CaTiO}_{3}$ ) during electrolysis. Fabrication and tests of a new and effective cathode assembly are reported by utilizing a $\mathrm{Ti}$ basket and Mo mesh to accommodate the hollow and fragile oxide precursors. This approach can obviate the need for sintering, reducing the time and energy consumption of the process as a whole. The produced near-net-shape samples possess a fine $\alpha$ - and $\beta$-phase structure and good mechanical properties that are comparable with natural bone and porous Ti-6Al-4V alloys produced by powder metallurgy. We hope this report has pointed a new direction for development of cost-affordable nearnet-shape production of engineering components with titanium and other metal alloys.

\section{ACKNOWLEDGMENTS}

The authors thank S. Fletcher for the initial interest and discussion, the East Midlands Universities Association (EMUA) for a Sport-Related Studentship to D. $\mathrm{Hu}$, the EPSRC for partial funding (EP/F026412/1 and $\mathrm{EP} / \mathrm{J} 000582 / 1)$, and D. A. Jewell for assistance in some early experiments.

\section{OPEN ACCESS}

This article is distributed under the terms of the Creative Commons Attribution License which permits any use, distribution, and reproduction in any medium, provided the original author(s) and the source are credited.

\section{REFERENCES}

1. D. Knittel and J.B.C. Wu: in Mechanical Engineers' Handbook, M. Kutz, ed., Wiley, New York, 1998, pp. 91-108.

2. G. Lütjering and J.C. Williams: Titanium, 2nd ed., Springer, New York, 2007.

3. C. Leyens and M. Peters: Titanium and Titanium Alloys: Fundamentals and Applications, WILEY-VCH, Weinheim, 2003.

4. R.R. Boyer: Mater. Sci. Eng. A, 1996, vol. 213, pp. 103-14.

5. H.J. Rack and J.I. Qazi: Mater. Sci. Eng. C, 2006, vol. 26, pp. 1269-77.

6. F.H. Froes: in Handbook of Materials Selection, M. Kutz, ed., Wiley, New York, 2002.

7. W. Kroll: Trans. Electrochem. Soci., Ottawa, Canada, 1940, pp. 35-47.

8. EHK Technologies: Summary of Emerging Titanium Cost Reduction Technologies, 2004, p. 59

9. F.H. Froes, and M. Ashraf Imam: Key. Eng. Mater, 2010, vol. 436, pp. $1-11$

10. D.J. Fray: Int. Mater. Rev., 2008, vol. 53, pp. 317-25.

11. G.Z. Chen, D.J. Fray, and T.W. Farthing: Nature, 2000, vol. 407, pp. 361-64.

12. D.J. Fray and G.Z. Chen: Mater. Sci. Technol., 2004, vol. 20, pp. 295-300

13. M. Ma, D.H. Wang, W.W. Wang, X.H. Hu, X.B. Jin, and G.Z. Chen: J. Alloys Compd., 2006, vol. 420, pp. 37-45.

14. W. Li, X.B. Jin, F.L. Huang, and G.Z. Chen: Angew. Chem. Int. Ed., 2010, vol. 49, pp. 3203-06.

15. C. Ohkubo, I. Watanabe, J.P. Ford, H. Nakajima, T. Hosoi, and T. Okabe: Biomaterials, 2000, vol. 21, pp. 421-28.

16. J.C. Li and D.C. Dunand: Acta Mater., 2011, vol. 59, pp. 146-58.

17. J.J. Peng, K. Jiang, W. Xiao, D.H. Wang, X.B. Jin, and G.Z. Chen: Chem. Mater., 2008, vol. 20, pp. 7274-80.

18. K. Jiang, X.H. Hu, H.J. Sun, D.H. Wang, X.B. Jin, Y.Y. Ren, and G.Z. Chen: Chem. Mater., 2004, vol. 16, pp. 4324-29.

19. G.H. Qiu, K. Jiang, M. Ma, D.H. Wang, X.B. Jin, and G.Z. Chen: Z. Naturforsch., A: Phys. Sci., vol. 62A, pp. 292-302.

20. D.W. Richerson: Modern Ceramic Engineering, 3rd ed., CRC Press, Taylor \& Francis Group, Boca Raton, 2006. 
21. G.Z. Chen, E. Gordo, and D.J. Fray: Metall. Mater. Trans. B, 2004, vol. 35B, pp. 223-33.

22. R.L. Centeno-Sánchez, D.J. Fray, and G.Z. Chen: J. Mater. Sci., 2007, vol. 42, pp. 7494-7501.

23. D.T.L. Alexander, C. Schwandt, and D.J. Fray: Electrochim. Acta, 2011, vol. 56, pp. 3286-95.

24. A. Roine: HSC Chemistry Version 6.12, Outokumpu Research Oy Information Service, Pori, 2006.

25. G.Z. Chen and D.J. Fray: J. Electrochem. Soc., 2002, vol. 149, pp. E455-E467.

26. K. Dring, R. Dashwood, and D. Inman: J. Electrochem. Soc., 2005, vol. 152, pp. E104-E113.

27. K. Jiang, X.H. Hu, M. Ma, D.H. Wang, G.H. Qiu, X.B. Jin, and G.Z. Chen: Angew. Chem. Int. Ed., 2006, vol. 45, pp. 42832.

28. R. Bhagat, D. Dye, S.L. Raghunathan, R.J. Talling, D. Inman, B.K. Jackson, K.K. Rao, and R.J. Dashwood: Acta Mater., 2010, vol. 58 , pp. 5057-62.
29. W. Xiao, X.B. Jin, Y. Deng, D.H. Wang, and G.Z. Chen: Chem. Eur. J., 2007, vol. 13, pp. 604-12.

30. Y. Deng, D.H. Wang, W. Xiao, X.B. Jin, X.H. Hu, and G.Z. Chen: J. Phys. Chem. B, 2005, vol. 109, pp. 14043-51.

31. T.K. Zhu and M.Q. Li: Mater. Charact., 2011, vol. 62, pp. 724-29.

32. F.X. Gil Mur, D. Rodriguez, and J.A. Planell: J. Alloys Compd., 1999, vol. 234, pp. 287-89.

33. J.J. Peng, H.L. Chen, X.B. Jin, T. Wang, D.H. Wang, and G.Z. Chen: Chem. Mater., 2009, vol. 21, pp. 5187-95.

34. K. Dring, R. Bhagat, M. Jackson, R. Dashwood, and D. Inman: J. Alloys Compd., 2006, vol. 419, pp. 103-09.

35. G.Z. Chen and D.J. Fray: Trans. Inst. Min. Metall. C., 2006, vol. 115 , pp. $49-54$.

36. A. Mitchell: $J O M, 1997$, vol. 49, pp. 40-42.

37. F.G. Evans: Artif. Limbs, 1969, vol. 13, pp. 37-48.

38. S.R. Bhattarai, K.A.-R. Khalil, M. Dewidar, P.H. Hwang, H.K. Yi, and H.Y. Kim: J. Biomed. Mater. Res., Part A, 2008, vol. 86A, pp. 289-99. 